\title{
JAX, THE ARCHITECTURE: \\ Designing a Chatboat Architecture to Reduce Ajax Fancare's Logistical Problem and Enhance Fan Experience
}

\author{
Steven Limandjaja ${ }^{1,2}$ \\ ${ }^{1}$ Creative Media and Game Technologies, Art \& Technology, Saxion University of Applied Sciences, M.H. \\ Tromplaan 28, $7513 \mathrm{AB}$ Enschede, the Netherlands. \\ ${ }_{2}^{2}$ Plakband Team, Digital Society School, Wibautstraat 2-4, 1091 GM Amsterdam, the Netherlands. \\ Email: steven_limandjaja@yahoo.com
}

\begin{abstract}
This paper is the documentation of a graduation internship at Digital Society School (DSS) in which they teamed up with Ajax Fancare to solve their logistical problem and enhance the fan experience. Ajax Fancare is facing a logistical problem in manually answering every fan's question via calls, emails, social media, or live chat. They believe that chatbot is the solution to this problem. The goal of this project is to research, design, and prototype a chatbot that could tackle the logistical problem and enhance the fan experience. The deliverable is a chatbot prototype and architecture in which Ajax Fancare could build upon for their future customer service chatbot. The main question of the research is answered by the chatbot architecture: Jax the Architecture, a conversational tree of all the possible interactions between a user and the chatbot. The final chatbot architecture answers the research question by mapping together the main elements of the chatbot such as the information fans needed from Ajax Fancare and additional features that create a new and inclusive experience. The prototypes and final chatbot architecture are ready to be tested for further research and serve as a cornerstone for future development of the Ajax Fancare chatbot.
\end{abstract}

Keywords: Chatbot architecture, Logistical, Fan experience.

\begin{abstract}
Abstrak
Tulisan ini adalah dokumentasi dari tugas akhir yang dilakukan di Digital Society School (DSS) dimana mereka bekerja sama dengan Ajax Fancare untuk memecahkan masalah logistik mereka serta meningkatkan pengalaman penggemar. Ajax Fancare mengalami masalah logistik dalam membalas pertanyaan-pertanyaan penggemar via panggilan, email, media sosial, atau live chat. Mereka percaya bahwa chatbot adalah solusi untuk masalah ini. Tujuan dari proyek ini adalah melakukan riset, desain, dan membuat prototipe chatbot yang mampu menangani masalah logistik serta meningkatkan fan experience. Hasil dari proyek ini adalah prototipe dan arsitektur chatbot dimana Ajax Fancare dapat membangun chatbot layanan pelanggan mereka di masa depan. Pertanyaan utama dari penelitian ini dijawab oleh arsitektur chatbot: Jax the Architecture, pohon percakapan dari semua kemungkinan interaksi antara pengguna dan chatbot. Arsitektur chatbot tersebut menjawab pertanyaan penelitian dengan memetakan unsur-unsur utama dari chatbot seperti informasi yang dibutuhkan penggemar dari Ajax Fancare dan fitur tambahan yang menciptakan pengalaman baru dan inklusif. Prototipe dan arsitektur chatbot tersebut siap diuji untuk penelitian lebih lanjut dan berfungsi sebagai landasan untuk pengembangan chatbot Ajax Fancare ke depan.
\end{abstract}

Kata kunci: Arsitektur, chatbot, logistik, pengalaman penggemar.

\section{Introduction}

In these digital times, we are always in contact with data, either physical or digital. Data is all around us, being produced, gathered and stored. With all this data around us, we could ask ourselves a simple question. How can we create something beneficial from those data? At the same time, the popularity of chatbots to automate customer service related tasks is growing. By 2020, it is expected that $80 \%$ of companies will use chatbots to do customer service related tasks. This trend creates a huge opportunity and prospect for the possibilities chatbots in the future (Oracle, 2016).

\section{Problem Indication}

The client of this project, the Ajax Fancare is interested on how we can use technology to create a unique and inclusive fan experience. Ajax Fancare mainly focuses on tackling their logistical problem which is answering each and every fan's question via calls, emails, social media, or live chat. They wanted something that could possibly automate the process, thus reducing the number of contact moments and at the same time improving the overall fan experience. They also aspire to be available $24 / 7$ and that is why they came up with the idea of a chatbot. They believe that chatbot could be the solution to their problem. 


\section{Preliminary Problem Definition}

It is made clear that Ajax wanted a chatbot. The requirements of the chatbot from Ajax Fancare are: it has to be Microsoft and able to answer the frequently asked questions. Other features are a plus to the chatbot. The expected outcome of this project is not the actual chatbot but a chatbot prototype in which Ajax Fancare could build their future customer service chatbot on. On the other hand, DSS is interested in researching how the chatbot can be something more than just an answering machine, how to give a meaningful value to the chatbot. One of the frameworks used in DSS' projects is the Sustainable Development Goals (SDG) by the United Nations (UN). The chatbot should also resonates with the SDG. DSS expect the chatbot to create inclusivity, which is one of the SDGs. Taking into account all the expectations of the stakeholders, the preliminary problem as formulated in the project brief is: How can interactive technologies, such as chatbots, be used to create an inclusive experience for fans?

\section{Main and Sub Question}

The team analyzed the problem and conduct preliminary research on the topic. After the preliminary research, a new main question is formulated.

\section{Main Question}

How to design a chatbot that tackles the logistical problem of Ajax Fancare and creates new and inclusive experience for Ajax Fans?

\section{Sub Questions}

1. What is fan experience in sports entertainment industry?

2. What are the principles of inclusivity and sustainability in design?

3. What is a chatbot?

- What are the UI/UX principles of a chatbot?

- How is the performance of the state of the art chatbots available?

- What are the tools to develop a chatbot?

4. What are the laws concerning privacy and data and their relation to chatbot?

5. What are the questions Ajax fans needed from Ajax Fancare?

6. Who are the end users and what can we learn from them?

7. How should we design the personality of the chatbot?

8. What features can we add to the chatbot to make new and inclusive fan experience?

9. What can we deliver to Ajax Fancare and what value does it have?

\section{Scope}

The project's scope consists of three main activities: research, design, and prototype. Developing a production-ready chatbot is outside the scope of this project. However, the team would go to a certain length in developing prototype(s) for this project. The main goal of this project is to deliver a prototype of a chatbot to be implemented by Ajax Fancare for their future customer service chatbot. A sub-of this is to deliver a guideline or frameworks on building the chatbot. It is expected that from this project, Ajax Fancare would have the resources needed to develop their future chatbot.

\section{Project Planning}

The team uses the SCREAM! approach, DSS' own version of SCRUM. It is proven to foster creativity better and improve the overall team productivity and collaboration (van Hout \& Gootjes, n.d.). The whole project lasted 18 weeks, divided into six sprints, three weeks in each sprint. In the beginning of each sprint, there is a sprint planning session. The sprint is divided into two halves. The first half of the sprint is the research part where the team will conduct desk research, literature studies, and brainstorming sessions. The second half is the making part, where the team design and builds the prototype or deliverable. Between the two halves, a translate session is held, joined by the whole team, the supervisor, the track owner and associates. In this session they discuss the research findings on the first half and decide what to be done on the next half. The sprint ends with a sprint review, joined by everyone at the translate session plus the other stakeholders. Here, the team will explain the research, prototype, and future plan of the project. This is also the moment for getting feedback from the stakeholders. At the conclusion of the sixth sprint, there will be a final showcase where the team and the other teams of the DSS will showcase their product.

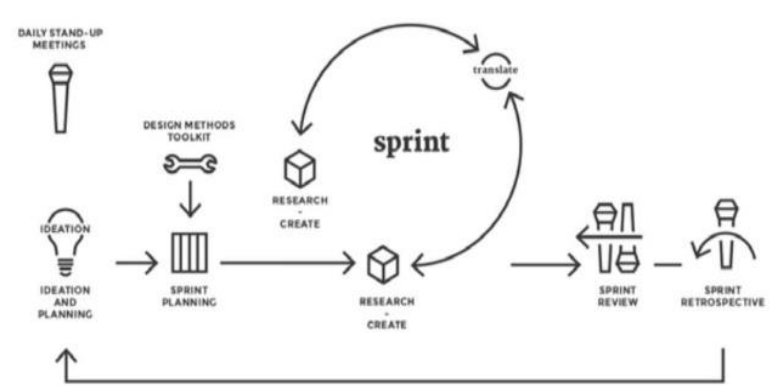

Source: SCREAM! An Integrated Approach for Multidisciplinary Design Teams in Higher Education

Figure 1. Scream! Approach 


\section{Project Stakeholders}

Digital Society School Digital Society School (DSS) is a research studio within Amsterdam University of Applied Sciences (HvA). At DSS, they research the impact of technology on society, develop the skills necessary to guide the transformation and pass on the knowledge and skills to a new generation of professionals (DSS, 2019). There are three tracks within the DSS. Those tracks are Digital to Physical, Data Driven Transformation and Systems for Sharing. This project falls under the Data Driven Transformation track and is supervised by Evelien Christiaanse.

\section{Lectoraat Crossmedia}

Lectoraat Crossmedia is a research body within the HvA. The Lectoraat is gave this project to the DSS, therefore they are one of our clients. Their main focus is to research how media companies can use the new possibilities of all kinds of media for better services and a reinforcement of the experience with their audience (CREATE-IT, 2017).

\section{Ajax Fancare}

Ajax Fancare is the customer service department within Ajax. They are the product owner or client of this project. Ajax Fancare is trying to tackle their logistical problem, which is answering the fan's question through emails, calls, and live chat which is the goal of this project. They, alongside with DSS, came up with the preliminary problem definition. They hope to automate the process and thus reducing the contact moments and at the same time improving the fan experience.

\section{Johan Cruijff ArenA}

In this project, we worked with Johan Cruijff ArenA's innovation team. They are the intermediary between DSS and Ajax Fancare. By the time this report is written, the ArenA and DSS have been partners for 3 semesters. The ArenA has an ongoing project called Change the Game. The main purpose of the program is to come up with new innovations to prepare the Arena for the 2020 Euro Cup.

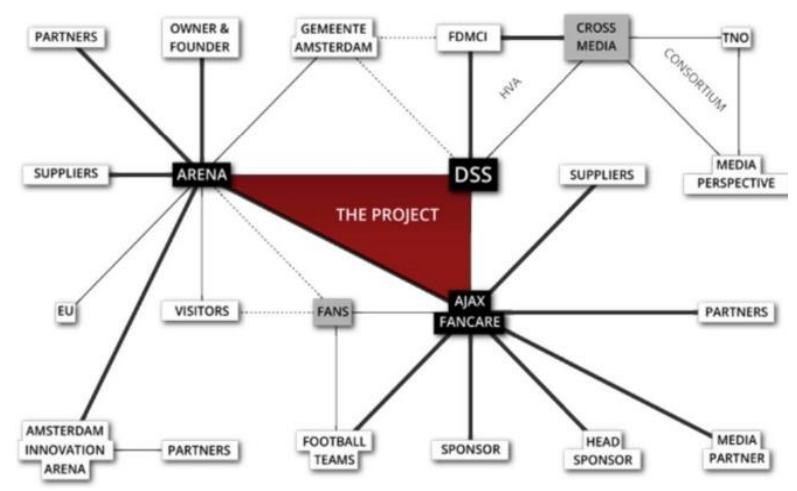

Figure 2. Project Stakeholders

\section{Theoretical Frameworks}

\section{Fan Experience and Trends}

Fan Experience in Sports Entertainment Industry Entertainment \& media businesses must be designed for the fans in order to capture strategic advantages, particularly in the sports entertainment industry. In sports entertainment, such as competition and matches, two or more teams compete with each other and there will be one winning team. That means that some of the fans will come home empty handed. Sports organizations should be able to create a good experience for each and every fan, even when their team is losing. That is one way to measure the success of a sport event. In the context of technology, the whole fan experience starts before the ticket purchase and peaks at the time of the actual game in the venue. The goal is to create the best experience on and off the field. With the current advancement of technology, especially in the mobile industry, sport organizations have the possibility to create more touchpoints to engage with the fans (Turnali, 2013).

\section{Trends in Sports Entertainment Industry}

In today's landscape, fan experience in sports entertainment industry is being redefined by a number of trends:

1. The Rise of Live Streaming Content creation tools (Facebook Live, Snapchat or Instagram Stories) can drive deeper engagement with fans than ever before (Decker, 2017).

2. Live Social Displays and In-game Experiences This refers to extending engagement with fans beyond apps, but also in-stadium. It could mean displaying content from Instagram stories live in-stadium, creating at the same time a huge market opportunity for live social media sponsorship (Decker, 2017).

3. The Rise of Game-enhancing Technology which Redefines Sports This refers to showing games in Virtual Reality or even Augmented Reality to bring the fan at the center of the experience. This could expand to virtual ticketing, or buying tickets for games that would be broadcast through VR or AR, making the concept of soldout stadiums a thing of the past (Decker, 2017) (Wang, n.d). This can also refer to better Wi-Fi access (Baumer, 2011), the set-up of fantasy zones for VR and AR, having holograms on the field instead of players to show a game in different locations, having TVs in the seats so that everybody can see the game properly and being able to hear live commentary or have personalized instant replays for each fan (Wang, n.d). 
4. Minimizing Time Away From The Game Stadiums are trying to find ways of reducing the time that fans spend away from the game, for instance waiting in concession lines or at the toilet. Some stadiums now offer the opportunity of ordering through an app and having the order delivered to the seat number (Wang, n.d) and some have TVs in the toilets that broadcasts the match (Baumer, 2011).

5. The Increase in Exclusive Content for Loyal Fans Loyal fans who typically represent 10 to $20 \%$ of a franchise's user base can drive up to $80 \%$ of the franchise's overall business value. There is a trend in content efforts prioritizing initiatives at serving loyal fans with exclusive content or deals that would increase video traffic. Fans can also be rewarded through digital currencies to drive then to use social media more, or to engage more with content distribution channels (Vollmer, 2017)(Wang, n.d).

6. Having More Flexibility about Ticket/Seat Purchases Utilizing real time seat upgrades and smart couponing to supplement revenues when the stadium is not full. Redefine the definition of a season ticket holder and changing ticket packages to maybe paying a monthly fee/subscription for a predetermined number of games so fans can have more flexibility about which games they choose to see and be allocated a different seat depending on the availability, thus offering unique experiences each time (Deloitte, 2018).

7. Transforming Stadiums in Social Environments Fans want to spend more time in multiple locations of the venue, to meet their friends and not be tied down to a single seating option. Some opportunities for this are media lounges, craftbeer gardens or sports bars overviewing the stadium, fantasy sport spaces or tech-infused retail. This can also refer to a stadall -a stadium and mall combination or to the creation of kid zones which can also be used to capture lifelong loyalty for the children who use them (Dimensional Innovations, 2018).

\section{Inclusivity and Sustainability}

Inclusivity in Design When it comes to people, there's no such thing as "normal". Designers often design something to people of a specific gender, age, culture, tech literacy, and physical ability and tend to exclude people who are not "normal". Designing inclusively doesn't mean making one thing for all people, but rather designing diverse ways for everyone to participate (Microsoft, 2016). Microsoft defined three principles of inclusive design in their 2016 publication Inclusive Microsoft Design:
1. Recognize Exclusion

Disability is not a personal problem. Disability is mismatched interaction between a person with the society, either physical, cognitive, or social. We can say that the people who experience problem with interacting as excluded. Exclusion can be temporary, situational, or permanent.

2. Learn from Diversity

Everyone has a different view on the world and nobody is able to understand everything. That's why it's important to learn from different people. Experience might be different between men and women or between a blind person and a person with a perfect eyesight. It is important to learn about these differences and adapt them in such a way that everyone is able to use the product.

3. Solve for One, Extend to Many

Everyone, at some point, will experience exclusion as they interact with designs. Designing for people with permanent disabilities might be a challenge, but the result can benefit a broader range of people like those who doesn't necessarily have a permanent disability, but is having a situational limitation.

\section{Sustainable Development Goals}

Every DSS' project resonates with the Sustainable Development Goals. The Sustainable Development Goals (SDG) is a set of goals defined by the United Nations. This Agenda is a plan of action for people, planet and prosperity. Ending poverty and other deprivations must go hand-in-hand with strategies that improve health and education, reduce inequality, and spur economic growth, all while tackling climate change and working to preserve our oceans and forests. According to their official publication, there are 17 SDGs which are an urgent call for action by all countries in a global partnership (Sustainable Development Goals, 2019).

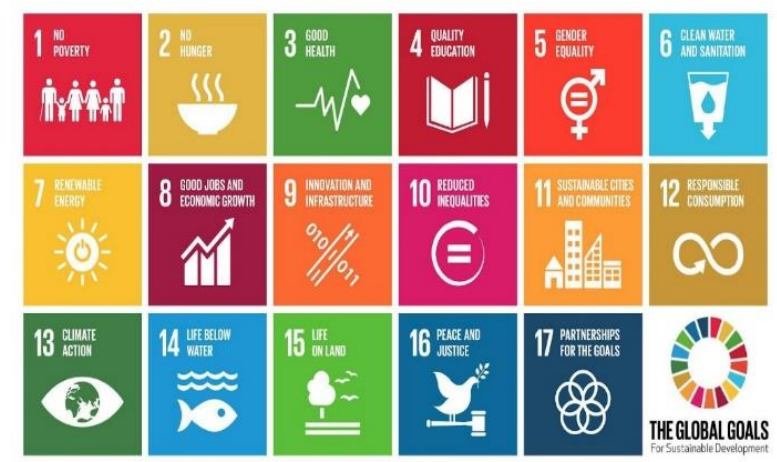

Source: https://sustainabledevelopment.un.org

Figure 3. Sustainable Development Goals 


\section{The Elements of Value Pyramid}

The Elements of Value Pyramid is one of the frameworks used in this project. It is a set of 30 values or fundamental attributes of a service/product in their most essential and discrete forms. The pyramid was first published on the September 2016 issue of Harvard Business Review. Those 30 values are divided into 4 categories/layers, in ascending order: functional, emotional, life changing, and social impact. In general, the more values are hit/fulfilled by a service/product, the greater the customer loyalty is, thus boosting the company's growth (Almquist, Senior, \& Bloch, 2016).

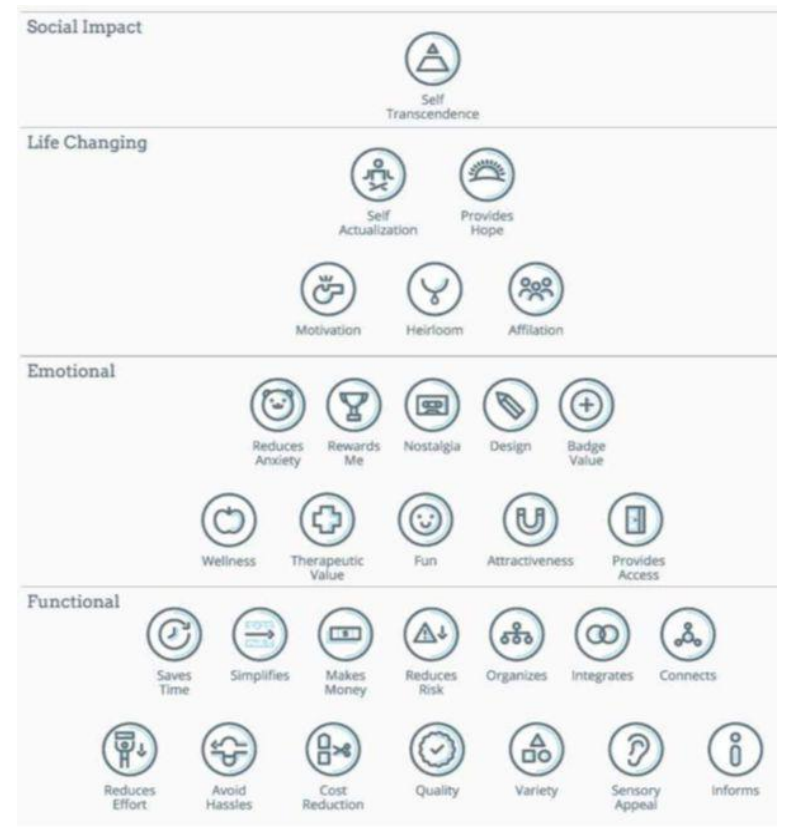

Source: https://hbr.org/2016/09/the-elements-of-value

Figure 4. Elements of Value Pyramid

\section{Designing a Chatbot}

\section{Introduction to Chatbot}

Chat Bots Magazine defined chatbot as "a service powered by rules and sometimes artificial intelligence, that you interact with via a chat interface" (Ismail, 2018). On the article The User Experience of Chatbots, Nielsen Norman Group (NNG) defined the six qualities of an intelligent assistant: voice input, natural-language processing, voice output, intelligent interpretation, agency, and integration of all the previous. From those six qualities, chatbot possess only two: natural language processing and intelligent interpretation. Which is why it is considered the poor relative of the intelligent assistant (Budiu, 2018).

\section{UI/UX Principles of Chatbot}

There are some principles to keep in mind in designing an interface or an experience.Creating a chatbot is no different, these are some principles in designing a chatbot:

1. Consistency. Just as in normal UI/UX-design, the design of the chatbot should be consistent. This applies not only to the interface elements such as buttons and list but also the UX elements like the tone of voice of the chatbot (Seo, 2017).

2. Not Making the Users Scroll. It is important that the user doesn't have to scroll up when reading the message because it is not a good experience. This can be done by making the text not overly long and considering the images or other visual elements shown to the user. Testing on multiple devices is recommend- ed to see if this problem occurs on any particular device since this might even be an issue on mobile phones or tablets because the keyboard is blocking parts of the screen (Seo, 2017).

3. Text and Button Input. There are two ways for users to make an input. They are typing (text) or with buttons (link). They had slightly different purposes: Text allowed users some flexibility in choosing the types of questions they wanted to ask and enabled them to deviate from the flow of the chatbot; Predetermined links and buttons saved users from typing. These were usually displayed in a carousel and could include images. People appreciated having these options and even expected them for common inputs. A good chatbot should have both options on how the user can make an input (Budiu, 2018).

4. Start-over Option. The user should also have the option to start over the conversation. This can simply be applied by providing a start-over button or a short explanation on how to start over (Seo, 2017).

5. Redirects. Redirects are used when the chatbot wants to show the user something that isn't available within the chatbot itself. When redirecting the user outside the chatbot, make sure the user knows that they are leaving the chatbot. On mobile phones or other platforms such as Face-book Messenger an option to use some kind of webview to open the webpage the chatbot is redirecting to might be a good idea (Seo, 2017).

6. Personality. Chatbots should have a personality, and it needs to be consistent throughout the whole conver-sation. A research by Nielsen Norman Group suggested that users were disappointed when a chatbot was not able to sustain that tone consistently throughout the conversation. Some chat-bots use informal language and talk in a friendly manner in the beginning of the conversation, thus making it more engaging. But once it got into the actual 
information they needed, it didn't really have the personality anymore; it was just straight clean cut information thus it can the users were unhappy (Budiu, 2018).

\section{Chatbot Design Framework}

Jesús Martín, on his publication Design Framework for Chatbots, defined four steps in designing a chatbot: the bot scope, the chatbot personality, a prioritized list of must-have features and the chatbot flow or architecture (Martín, 2017).

1. Chatbot Scope Defining what is the scope of the chatbot and make clear what people can expect from the chatbot. It helps the designer to focus on what actually matters.

2. Chatbot Personality Defining the chatbot's personality. Research should be conducted to get a clear picture of how and when the target user talks with the chatbot to determine the personality and tone of voice of the chatbot. Personality is one of the most important elements of the chatbot. This point resonates with the mentioned research by NNG.

3. Must-Have Feature List Making a list of what information/feature any user would need from our chatbot to find it useful.

4. Chatbot Architecture The architecture/chatbot flow is the most complex part of the chatbot and the blueprint of the chatbot. Once all information is available, it is time to design how the chatbot would behave/react in every possible scenario of interaction with the user. The final chatbot architecture, is the foundation and the most valuable element of the chatbot.

\section{Chatbot Benchmarking}

As part of the research, the team conducted a benchmarking test on chatbots. The goal of this benchmarking is to get an overview of some state-ofthe-art chatbots and help the team set the standard of the Ajax Fancare chatbot. In total there are seven chatbots benchmarked. The benchmarking result indicates that most of the advanced chatbots, such as Siri, Alexa, and Cortana use AI technology behind it. For simpler chatbots that don't use AI, they perform well as long as the user doesn't break out of the chatbot's intended flow.

\section{Tools for Developing a Chatbot}

\section{Adobe XD}

Adobe XD is a software developed and published by Adobe Inc for designing and prototyping user experience for web and mobile apps. Adobe XD makes it possible for designers to seam- lessly create, iterate and share interactive prototypes with team members and reviewers across devices and platforms. It's main features are vector design, website wireframeing, and creating simple interactive click-through prototypes. It is however a tool to create a prototype, and not the end product (Lardinois, 2016).

\section{Flow.AI}

Flow.AI is a platform/service to create Chatbots, AI assistants, Customer service or conversational commerce solutions. It offers an easy drag and drop interface coupled with advanced functionality and driven by powerful NLP. Flow.ai offers multiple languages, multiple channels and functionality to let human agents take over conversations (Flow.ai, 2019).

\section{Microsoft Azure's QnA Maker}

QnA Maker is a cloud-based API service that creates a conversational, question and answer layer over your data. QnA Maker enables you to create a knowledge-base (KB) from semi-structured content such as Frequently Asked Questions (FAQs), URLs, product manuals, support documents and custom questions and answers. The QnA Maker service answers users' natural language questions by matching it with the best possible answer from the QnAs in the Knowl- edge base (What is QnA Maker, 2019).

\section{Privacy and Data}

\section{GDPR on Chatbots}

The General Data Protection Regulation (GDPR) are the guidelines that regulates data protection for the citizens in the European Union (EU). In 2016 the final version of the GDPR was approved by the EU Parliament. After a two-year waiting period the regulation is enforced on 25 May 2018. The GDPR makes it mandatory for every organization that does business in or with the European Union and that collects and processes information related to EU citizens, to follow the regulations. Where the companies are from or the data is kept does not matter (Tan- kard, 2016) (GDPR, sd). To make a chatbot GDPR compliant it has to address how and why it collects the personal data of customers. An online chatbot most likely needs personal information to provide customers a personalized experience. However, according to the GDPR guidelines companies need approval from the customers to use their data. This should be asked in the beginning of the conversation. The privacy policy should also be shown to make clear how and why the data of consumers is used by the chatbot. Further the GDPR states that companies must provide users access to the data collected by the chatbot, and also need to be able to delete certain data if they want (Clickatell, sd). Another thing to note is that AI 
technology should not make decisions alone, humans have to have influence in the decisions that deal with personal information. Logs that are kept by the chatbot might hold personal data, such as IP addresses and names. Organizations are not allowed to store this data without explicit consent of the consumer or if there is no legitimate reason to store it. Once they have collected the data with the use of a chatbot, companies have to follow the strict secure data processing regulations, as stated by the GDPR (Clickatell, sd).

\section{People's Perception on Data Collection by Chatbots}

A research was conducted by Jai \& King (2016) to find out how people think of personalized services that are based on their data and what data they would allow companies to have about them. The research suggests that companies that want personalized contact with their customers should focus on the younger audience, namely people between 18 to 24 years old. The reason behind this is that people from that age group are more open to the idea. This also applies for the use of a chatbot, the younger group are more willing to share personal data to get a personalized experience. However, companies and chatbots should only use the data the consumer shared and not use third party data. As soon as the chatbot starts to use third party data and integrate it with the conversation with the chatbot, users from all age groups will be perceived as 'creepy' (Jai \& King, 2016).

\section{Research Methodology}

\section{Desk Research}

Desk research consists of gathering information that is already published either in print or online. The findings of the desk research are then presented during the translate session to be discussed with experts to be analyzed and applied to the project. The research was conducted with university standards and reviewed by qualified experts.

\section{Survey}

Survey is the collection data or information from a large number of people. The team conducted a survey to gain insights from user. The survey conducted by the team were reviewed by the company before it was released. The survey answers are filtered so that only valid answers are counted.

\section{Observation}

Observation is the practice of observing the user to understand their behavior. The team conducted two observation sessions on site to observe fan's interaction with other fans, with their phones, and their overall behavior in the stadium. The team had prepared a guideline to be used at the actual observation.

\section{Benchmarking}

Benchmarking is the practice of comparing the process or performance of a product or service and comparing them with other similar product or service. The team used this method to examine the quality and experience of the currently available chatbots.

\section{Prototyping}

Prototyping is the making of a prototype to simulate the final product. The quality of a prototype range from a simple paper prototype to a sophisticated working chatbot prototype. A number of prototypes were made for this project as explained in the paper.

\section{User Testing}

User testing is a method used to test the quality of the prototypes. The latest prototype, the Microsoft prototype is user tested internally by the people at the studio and the stakeholders. Their feedback is taken into consideration for further development of the prototype and the team used the tester's input as training data for the chatbot.

\section{Research Result}

\section{Ajax Fan's Logistical Question}

\section{Information Sources}

The minimum functionality of the chatbot is to answer the logistical questions of the fans. To get the information on questions fans generally ask, the team extracted information from the following sources:

1. Ajax Website: Information collected from the FAQ section of the official Ajax website. These informations are legitimate, however they are very general and low in quantity.

2. Johan Cruijff ArenA Website: Information collected from the FAQ section of the official Johan Cruijff ArenA website. These informations are legitimate, however they are very general and low in quantity.

3. Social Media: Information collected from social media, mainly the tweets to and from @Ajax Fancare. They are collected through scraping the Ajax Fancare twitter using Twitter API.

4. Online Forum: Information collected from online forums such as Reddit. These informations are not from Ajax but from fans, thus the reliability of the information are questionable and needed to be checked.

5. Knowledge Base: A Knowledge Base (KB) is a set of questions and answers. We received some sets of knowledge bases created by Ajax Fancare. 


\section{Segmentation from Topics}

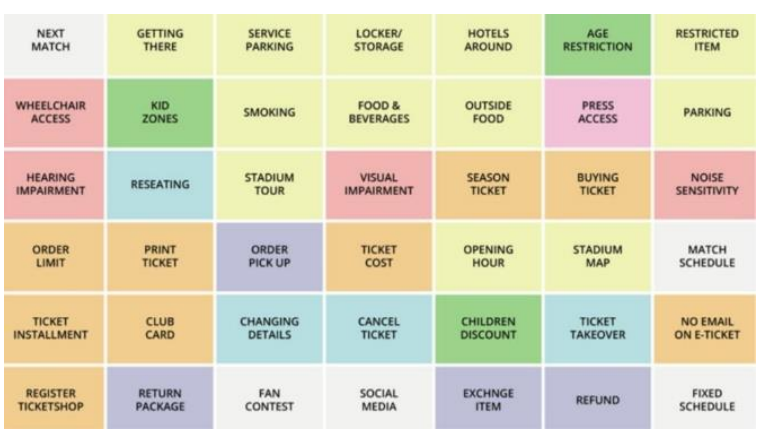

Figure 5. Adobe Xd Prototype

The information collected from the sources mentioned in chapter 3.2.1 (excluding the Knowledge Bases) are then clustered into what would later become the Adobe Xd prototype. Each topic are color coded based on different needs. White: General Ajax information; Yellow: General ArenA information; Red: People with special needs; Pink: Press; Blue: People who needs flexibility; Green: Families This model helped the team in mapping the available information on Ajax on the internet, thus pointing out which information is still not available. It also gives new insight by identifying a new segment, which is Press. Press as a segment is a new finding for Ajax Fancare. This information suggests that not everyone in the stadium during the match is a fan, but could be a press doing their job in covering the match.

\section{The User}

The target user of the chatbot is every Ajax fan. However, Ajax Fancare wanted to focus on a specific segment. At the first sprint review, the target are narrowed to two segments: families and football lovers. By the third sprint, the target is narrowed to just one specific segment which is families. The reason is, families are a big portion of the total fans that are often neglected. This doesn't mean the chatbot exclude the other segments, but instead focus on creating inclusive features for the families. In the end, every Ajax fan could use and benefit from the chatbot and not just the families. This decision in focusing on families resonates with Microsoft Inclusive Design's principle "Solve for One, Extend to Many" mentioned in chapter 2.2.1.

\section{Ajax Fan Personas}

The team created six personas of the possible end user of the chatbot, three families and three football fans. The personas are generated randomly and made to be inclusive and diverse to all end users. This chapter will only cover the targeted segment which is families.
1. De Jong Family

Bruce (47) and Karlijn (45) is a big fan of Ajax and always wanted to see a game. They live in Zwolle. Bruce doesn't mind going to a game because he is a fan as well as Karlijn. They are constantly looking for experiences that they can enjoy together. They see this as a special occasion so they don't have a pre-determined budget. They want to see a football game as a family trip. They want something to eat and drink during the game and they want to buy a souvenir, when the game is finished.

2. Huisman Family

Henk (60) takes his son (30) and his nephew (28) to the ArenA on a regular basis. They've been doing this for years. They're all adults now and they still follow this tradition. They don't live together so they'll have to carpool. They will all pay for this trip. They expect from each other to give a round of food or drinks. They want to do something after the matchbut they need to go home afterwards. Someone needs to BOB. They haven'tdecided where they want to socialize.

3. De Boer Family

Donald (40) watches every game. He enjoys sharing time with his son and daughter who also like football and are growing fans of Ajax. Charles (9) and Meghan (14) also plays in the local youth team. They live in Almere. Charles wants to be a professional football player when he grows up. The children like Ajax merchandise and have shirts, scarfs and other Ajax elements, more than Donald does. The family wants to see an exciting game and they care about which opponent they're playing against. Charles doesn't care about that. He only wants to see the stadium and his favorite players.

\section{Ajax Fan Motivation}

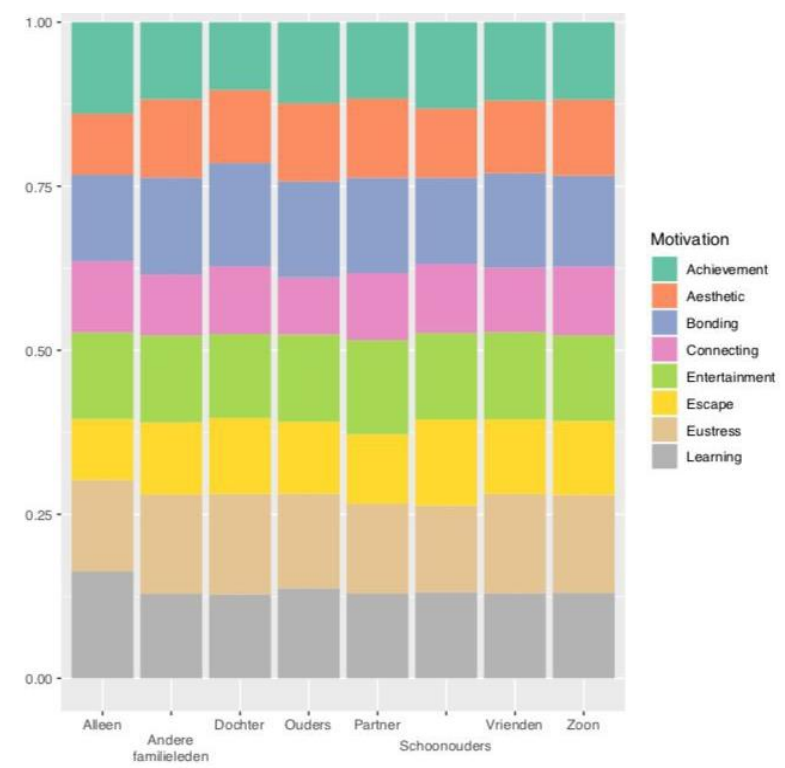

Figure 6. Fan Motivation Survey Result 
A survey was conducted in order to find out more about the drivers and motivations of Ajax fans who visit Ajax games at the Johan Cruijff ArenA. The purpose of the survey was to gather insight into the motivations of the fans attending the games so that we could enhance the fan experience through features that fit the motivations expressed by different segments. The survey methodology used 8 fan motivations derived from Performance Communication's Future Fan Framework: Escape, Eustress, Aesthetic, Achievement, Entertainment, Learning, Connecting and Bonding (Performance Communication, n.d.).

The 12 questions of the survey were connected to various motivations, giving insight into how each segment ranks on every motivation. The features were also connected to different motivations: for instance, the trivia game is connected to entertainment and providing hope feature is related to learning. Figure 12 is the result of the survey (See Appendix D). Out of 168 respondents, there are 106 valid responses. The two top motivations overall for all segments were Entertainment and Eustress. The lowest motivation was Connecting. The team found out that the composition of all motivations is very similar for all segments. As such, the survey was used to decide which features to prioritise and recommend to the client.

\section{Ajax Fan Behavior at the ArenA}

The team conducted two observations on Ajax Fans. The first observation took place outside the ArenA during the Champions League Semi Finals between Ajax and Tottenham Hotspurs. The second observation took place inside the ArenA during the Eredivisie finals between Ajax and FC Utrecht. The goal of the observations are to get insight on their behavior and interaction with other fans and with their phones before, during and after a football match so that we can taylor time specific features to the chatbot. A guideline with list of things to be observed was prepared beforehand to be used and filled during the observation. From the observations the team learned the following:

\section{Before the game}

1. Many people use their phones to take pictures, call and/or text family or friends.

2. Little to no fan engage with other fans outside of their group During the game.

3. Little to no fan use their phones.

4. Fan engage in small talk about the game with other fans outside their group.

\section{During the break}

1. The majority of fans use their phones to check social media and/or game statistics

2. Many fans go to get more food and/or drinks

3. Many fans go to the toilet

\section{After the game}

1. Many fans go to the toilet

2. Most fans get out of the ArenA immediately

\section{Personality of the Chatbot}

The team had a conversation with Jorna Post, the speech coach at Ajax. Jorna is responsible in standardising how Ajax (as a brand) talks to fans. We learned that Ajax speaks ifferently when talking to different fan segments. For example, The fancare team has the guideline on when to use either jij or $\mathrm{u}$, depending on factors like their age, type of membership, and topic -in Dutch, there are two ways to say the English word you (singular). In the case of the chatbot, the goal is to make the fans feel like they are talking to a fellow Ajax fan, because no one can engage with a fan better than another fan. The chatbot should have the characteristic of a good fan, such as friendly, enthusiastic, and optimistic. Another important thing is to make sure that the fans know that they are talking to a chatbot. The chatbot has human-like characteristic, however it should not (try to) be human. This also means that it has no gender. It is best that the fans are aware that they are not talking to a real human being. This way we can manage any expectations as to how smart the chatbot is. In the end, all those personality and traits are put together into a persona named Jax, the visual representation of the chatbot. The visual representation compliments and completes the personality it has.

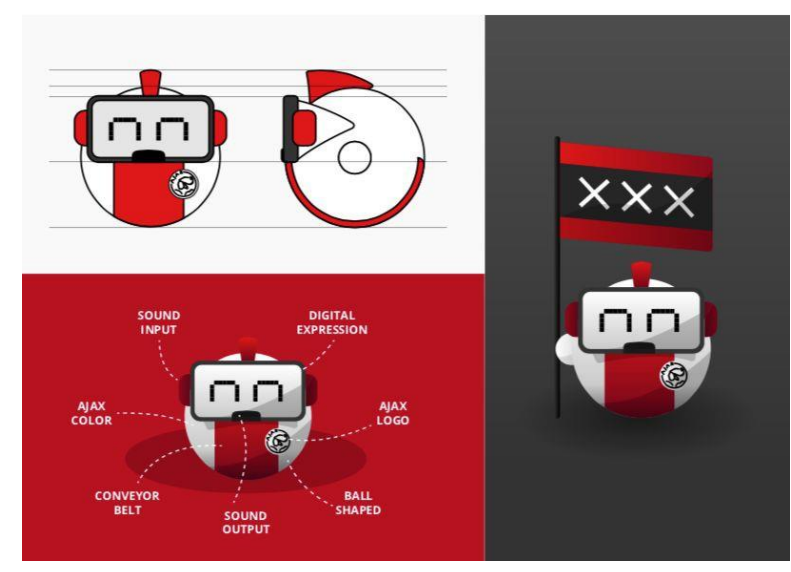

Figure 7. Visual Representation of Jax

\section{The Values of the Chatbot}

Looking back at the Elements of Value Pyramid, this sub-chapter explains the concepts made for the chatbot in order to hit the values of the pyramid.

\section{Functional Layer}

The functional layer of the Elements of Value Pyramid is the base of the pyramid. The values on that layer are physiological and safety needs. From 
fourteen elements on the functional layer, the final chatbot will hit at least these values: Saves Time, Simplifies, Reduces Effort, Avoids Hassles, and Informs. Those values are the usual and expected values of a chatbot. Therefore, if the chatbot is well designed and developed, those values should be fulfilled on its own. Due to time constraints, the team decided to move on to the upper layer instead which gives more meaningful value instead of trying to hit all the functional elements.

\section{Emotional Layer}

Unlike the functional layer, the product must be designed in such a way to hit the emotional values. It is unnecessary to hit every value so it is wise to focus on some that are relevant. For the chatbot, a discussion with stakeholders were held to determine which values to focus on. The chosen values are: Fun \& Entertainment, Reduces Anxiety, and Nostalgia. The team then came up with six concepts that are relevant with those three values, the Sustainable Development Goals (SDGs) and possible within the boundaries of a chatbot.

1. Navigation Assistant

A feature that makes it easier for fans to navigate within the ArenA. This feature would be helpful for people who do not visit the ArenA regularly. The chatbot would have a map / layout of the Arena, with transit instructions (tips) of the best way to get from the starting point to the desired point. Value: Reduces Anxiety. SDG: 9. Industry, Innovation, and Infrastructure.

2. In-seat Ordering

A feature that allows visitors to order food and beverages through the chatbot and have it delivered to their seat. Delivery can happen during the match time so people won't be worried to miss anything. This feature resonates with Jefferson Wang's report Top Ten Trends on the Digital Fan Experience (n.d.). Value: Reduces Anxiety. SDG: 17. Partnerships to achieve the Goal.

3. Karaoke

A feature in the chatbot where people can read the lyrics of the songs commonly sung on a match in the ArenA. It is designed to make it easier for new fans to engage with the stadium experience by singing the Ajax songs. Value: Fun \& Entertainment. SDG: 11. Sustainable Cities and Communities.

4. Sentiment Analysis

A feature integrated in the chatbot to detects whether the user feedback / input received is positive, neutral or negative with a classifier.
The chatbot would then respond a sentimentspecific reply based on the user's sentiment. This feature can also be used for fan segmentation purposes. Value: Reduces Anxiety. SDG: 9. Industry, Innovation and Infrastructure.

5. Family-friendly Measures

A feature in which the chatbot proactively gives information about the safety measures taken by the Johan Cruijff ArenA to ensure that families have a secure and memorable experience at all Ajax games. The information is specifically targeted at families and their needs to feel secure and meant to attract more families to the games. Value: Reduces Anxiety. SDG: 9. Industry, Innovation and Infrastructure.

6. Trivia Game

A trivia game within the chatbot. The game focuses on Ajax's history and league facts and has the purpose of engaging the fans in fun competitions, strengthening their connection with Ajax as a football club and brand and teaching the younger fans about the history of the club. Value: Fun \& Entertainment; Nostalgia.

\section{Life Changing and Social Impact Layer}

The life changing layer and social impact layer are the top two layers on the Elements of Value Pyramid. Just like the emotional layer, the chatbot must be designed in a way so it could hit the values in these layers. This time, the team could see two possible features that could possibly hit the values in the life changing and social impact layer.

1. Live Match Data Notification

Notification based feature through which the chatbot analyses live-match data and sends positive messages to give hope to people about the outcome of the game. Value: Provides Hope.

2. Personalized Thank You Message

A feature which sends customized messages/ pictures/gifs/videos to the fans present in the stadium at the beginning of the game and at the end. The messages are personalized based on the segments and aim to provide the fans with a sense of belonging and personal accomplishment for supporting the team. Value: Self Actualization; Affiliation \& Belonging.

\section{Prototypes and Deliverables}

\section{Adobe Xd Prototype}

The Adobe Xd prototype is the prototype made with Adobe Xd. It is the outcome of the first sprint. The prototype is not a chatbot but an interactive Q\&A. It is a collection of topics of questions collected from the internet. The raw data are clustered into 42 
topics. The topics are linked to the answers/ information that will be triggered when the topic is clicked. Refer to figure 5 for visual representation of the prototype. The user can click on any topic and they will get information on the topic. There are no architecture or conversational trees in this prototype. All conversations are linear and they can't branch off. The purpose of this prototype is to map the available information on Ajax on the internet and to serve as a conversational object during the first sprint review.

\section{Flow.AI Prototype}

The Flow.AI Prototype is the first chatbot prototype. The development of the Flow.AI prototype begins on the second sprint by converting the information collected for the first prototype into conversational flows in Flow AI. At this point, the development of the prototype has started even before the architecture was designed. This is not the ideal way to work. As mentioned on Jesús Martín's Design Framework for Chatbots (2017), the architecture is supposed to be done before any development started. Because of that, the team had to rebuild the whole chatbot flows all over every time a change is made to the architecture. The team eventually learned it in later in the process after a third re-organization of the architecture.
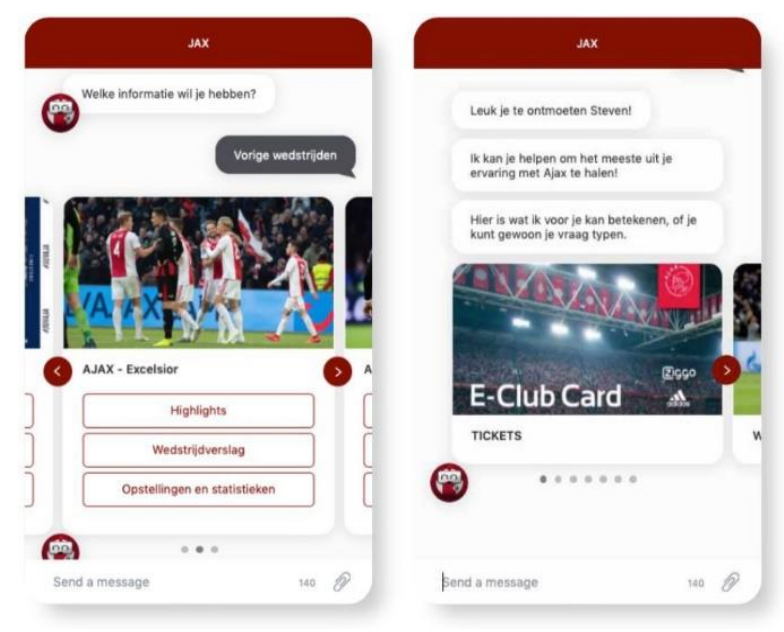

Figure 8. Flow.AI Prototype

\section{The Workflow}

This prototype is a chatbot, the idea is the user type a question (intent) and they will receive the answer. Each flow begins with an intent and followed by a set of actions. Those actions are the response to the user. The response can be a text reply, follow up questions, cards, links, or other interactive elements. There are 58 flows in the Flow.AI prototype. When a user asks a question, the Natural Language Processing (NLP) analyzes the question and put it on the right intent. The triggered intent would then trigger the following actions on it's flow. For each intent, a training data of at least ten rephrasings of the intent must be trained to Flow.AI. The prototype is regularly tested by the team by using different rephasing to see if the chatbot could detect the question to the intent. If the chatbot could not understand a rephrasing of an intent, then that rephrasing is fed manually to the respective intent's training data, thus improving its quality.

\section{Specification and Features}

The prototype has interactive elements such as menu, quick replies, buttons, cards built in FLow.AI. Users can get the information they needed by just following the menu options and choosing quick reply or button inputs. However, the benefit of using an intents for every topic is the users can always jump to a specific flow by giving text input that would then be detected and put on the right intent by the NLP.

Since the second sprint review, the team followed the stakeholder's request and changed the language of the chatbot from English to Dutch. The main reason is Ajax Fancare planned to actually implement the chatbot for their Dutch Ajax Fans.

\section{Online URL}

https://widget.flow.ai/try/MWZmYWVmNDAtZmU 3NS00MWYyLWIxMTAtN2ViOTg5Yjk3MDQxf\% 20

GRhYmM1MjcyLTMzODYtNDgyMi05NWJILWN $\mathrm{lMmVjODMyZDIzNg==}$

$\begin{array}{lll}\text { Language } & : & \text { Dutch } \\ \text { Personality } & : & \text { Yes (Jax) } \\ \text { NLP } & : & \text { Yes } \\ \text { Menu } & \text { Yes } \\ \text { Buttons/Quick replies } & : & \text { Yes } \\ \text { Decision branching } & : & \text { Yes } \\ \text { Self Learning } & : & \text { Yes } \\ \text { Sentiment Analysis } & : & \text { No } \\ \text { Redirects } & : & \text { Yes } \\ \text { Takeover } & : & \text { No, but possible } \\ \text { Implemented Features : } & \text { Family Friendly } \\ & & \text { Measures, Karaoke }\end{array}$

\section{Microsoft Prototype}

The Microsoft Prototype refers to the chatbot prototype made with Microsoft Azure. The Microsoft prototype is the second chatbot prototype. The development of the Microsoft prototype begins at the fourth sprint and it is the response to Ajax Fancare's requirements for the final chatbot addressed at the end of the third sprint (See Appendix H). 
The major reason is Ajax's commitment to Microsoft. Minor reason that was taken into consideration is using Azure opens more possibility of integration with Ajax Fancare's system since it is the working environment of Ajax Fancare.

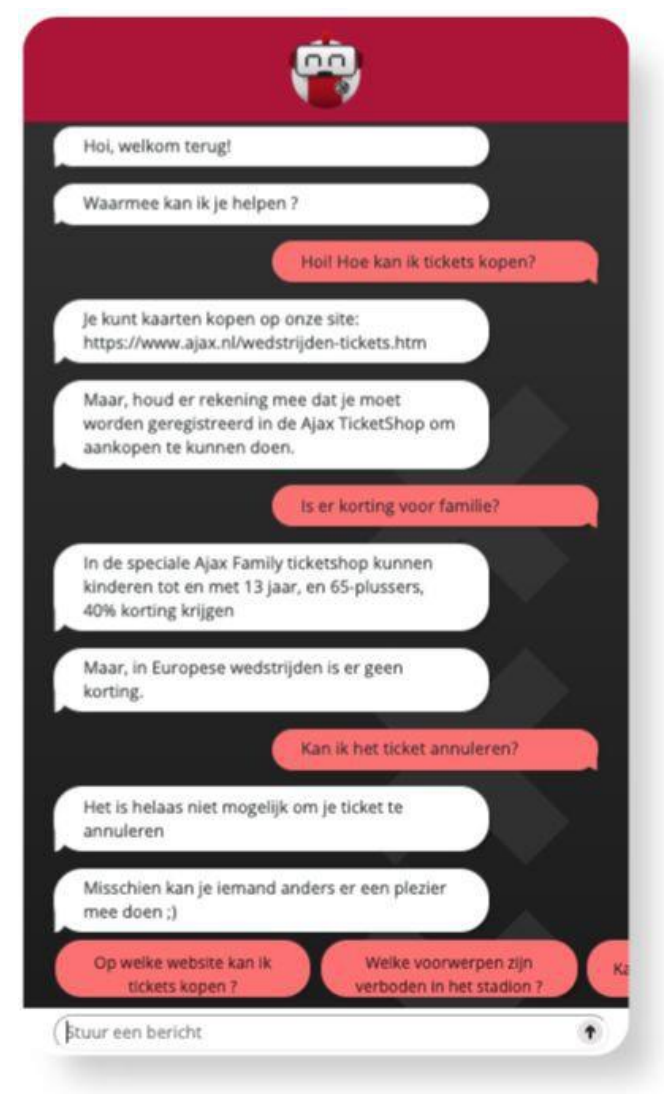

Figure 9. Microsoft Prototype

\section{The Workflow}

This prototype uses similar concept with Flow.AI. However, more programming is required since it is not a drag-and-drop service like Flow Ai. At this point, the Flow Ai prototype are kept as a reference and model. The KBs from the Flow Ai prototype were exported as CSV file and then be fed to the Microsoft prototype's KBs. The two main Azure services used to develop the prototype are Language Understanding Intelligent Service (LUIS) and QnA Maker. Figure 10 illustrates the workflow of the Microsoft prototype.

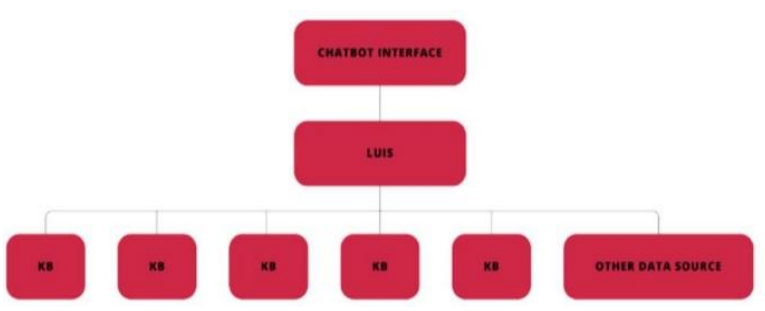

Figure 10. Microsoft Prototype Workflow
The text that the user input on the interface will be checked by LUIS. Using it's NLP capabilities, LUIS redirects the users input to the detected $\mathrm{KB}$ where the intended intent is located. The triggered intent will then return an answer to the user through the chatbot interface.

\section{User Testing}

User testing of the Microsoft prototype is conducted internally within the DSS studio and the stakeholders. Testers were given the URL of the prototype and were asked to try out the chatbot. Their feedback is then taken into consideration for further development.

However, the main reason for the user testing is rather to train the prototype. Just like Flow AI, the Microsoft prototype needs training data. For every input or question the testers asked, the prototype gets training data.

\section{Specification and Features}

Due to time constraints it is not possible for the team to replicate the whole Flow AI prototype in Azure. In the end, only ticketing related flows and the sentiment analysis feature are implemented on Microsoft Azure. The sentiment analysis is a feature that the Flow Ai prototype doesn't have. It is a builtin feature inside Microsoft Azure. Following the GDPR Guidelines, the team added a privacy policy message at the beginning of the interaction with the chatbot.

Online URL

https://arena.dss.cloud/

* Chrome or Firefox only

$\begin{array}{ll}\text { Language } & : \text { Dutch } \\ \text { Personality } & : \text { Yes (Jax) } \\ \text { NLP } & : \text { Yes } \\ \text { Menu } & : \text { Yes }\end{array}$

Buttons/Quick replies : No, but possible

Decision branching : Limited in current

Self Learning $\quad$ : Yes

Sentiment Analysis : Y Yes

Redirects : No, but possible

Takeover : No, but possible

Implemented Features: Sentiment Analysis

\section{Jax: Chatbot Architecture}

Jax the Architecture is the name of the final chatbot architecture of this project. It refers to the conversational diagram of all the possible interaction between the user and the future Ajax Fancare chatbot. The designing process of the Jax architecture begins around the same time the development of the Flow Ai prototype started. This is not the ideal way 
to work. The architecture should have been made final before any development starts.

Jax the Architecture is the successor of the Flow Ai's architecture. The team regularly make iteration and changes the chatbot architecture from the beginning of Flow Ai prototype (second sprint) up to the last sprint (sixth sprint) when it was finalized as the final chatbot architecture.

Because of the size of the architecture, it could not fit into the report. A sample of one section of the architecture showing the takeover flow is provided below. For the full architecture and legends, refer to this URL: https://drive.google.com/file/d/1Xmfd1bhv4LWN8k FOCWDs5b1tNzWwXE21/view?usp=sharing

The team believe that is how the ideal Ajax Fancare chatbot architecture should look like. The final architecture ties the research, design, and prototype together. All the essential elements of the chatbot, the personality, the fans' questions, the features, inclusivity are covered in the architecture.

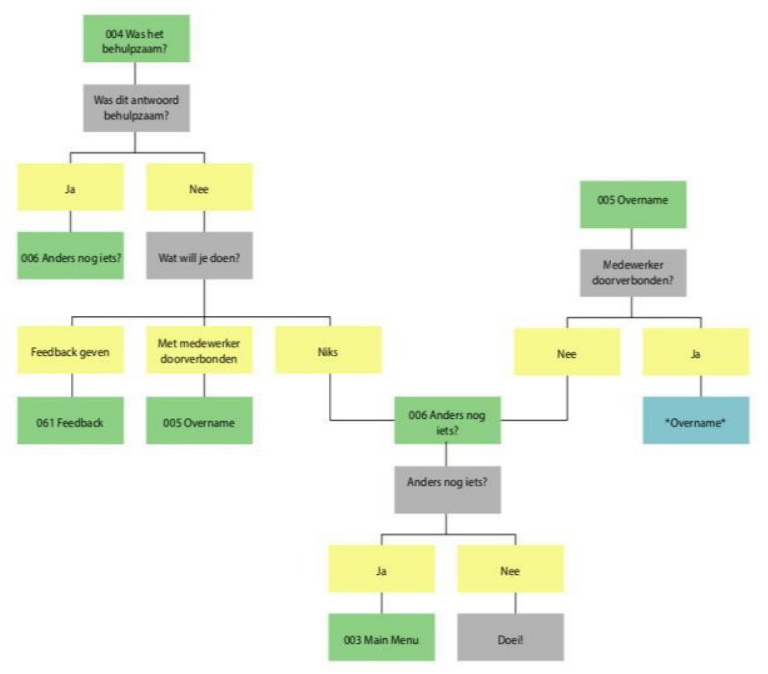

Figure 11. Takeover Flow of the Architecture

\section{Conclusion and Discussion}

\section{Conclusion}

Utilizing a chatbot to automate customer service related task is a growing trend. By 2020, it is expected that $80 \%$ of companies will use chatbots to do customer service related tasks (Ora- cle, 2016), Ajax Fancare is one of them.

The goal of this project is to design a chatbot to tackle the logistical problem of Ajax Fancare and at the same time create better and inclusive experience for Ajax Fans. To answer that question, the team is expected to deliver a prototype of the chatbot to be implemented by Ajax Fancare for their future customer service chatbot.
The team had conducted research to investigate how to design a good chatbot. The team found frameworks and design guideline on designing chatbots. The team concluded that these frameworks and guidelines are very useful in the design process of the chatbot.

It can be concluded that the project had reached its goal. By the end of the project, the team had made chatbot prototypes and a final chatbot architecture to be delivered to Ajax Fancare. The prototypes are ready to be tested for future research and development of the Ajax Fancare chatbot.

The team found that final chatbot architecture is the most valuable element of a chatbot and should be done before any development starts. This finding resonates with Jesús Martín's Design Framework for Chatbots (2017) where he stated the same. The final chatbot architec- ture, Jax the Architecture, ties the whole project together and answers the main question of this research. All the essential elements of the chatbot such as fan's logistical questions, the personality, and the concepted features are included in architecture.

However, due to the limitation of the project and the team, further research and development is still needed. Future research needs to be conducted to test the effectiveness of the final architecture. Also, further development is needed to develop the actual Ajax Fancare chatbot and to make it perform the way it is designed in the architecture.

\section{Discussion}

Chatbots have more potential than just answering questions. It can be used as a tool to build experiences. The team used the Elements of Value Pyramid by Bain as a framework to add values to the prototype but other frameworks can also be used. Making a chatbot can be divided into two main stages: design and development. There are principles and guidelines that can be helpful in designing a good chatbot. Examples of such guidelines and frameworks can be found in the paper. There are many tools available to create a chatbot. The team worked with two tools (Flow AI and Microsoft Azure) and can conclude that every tool has their pros and cons, so it is important to understand the scope and scale of the chatbot and then consider which tool fits the best.

Whichever tool you will use to develop the chatbot, it is always good to first have a good chatbot architecture. Architecture is part of the design of the chatbot so have a good architecture before starting the development. 


\section{Recommendation}

1. Establish the requirements at the very beginning.

Be specific about the requirements of the projects like what tools to be used and list of must haves. It is necessary to discuss the requirements and make an agreement with the stakeholders in the beginning of the project. Changing the tool or platform in the middle of the project is very inefficient.

2. Invest in making a good architecture.

From this research, it can be said that the architecture is the most important element of the chatbot. It is much easier to develop the chatbot when the architecture is well designed so do invest time and resources in designing a good architecture.

3. Develop only after the architecture is finalized. It is highly recommended not to start developing the chatbot immediately before the design process is done. There are frameworks to support this recommendation. Developing the chatbot before having a finalized architecture would cost rebuilding the chatbot every time a change is made to the architecture.

\section{Refferences}

Almquist, E., Senior, J., \& Bloch, N. (2016). The Elements of Value. Retrieved from hbr.org: https://hbr.org/2016/09/the-elements-of-value

Baumer, K. (2011, March 9). 14 Innovations That Will Make Sports Stadiums Of The Future Unrecognizable. Retrieved from businessinsider.com: http://www.businessinsid-er.com/ sports-stadiums-innovations-2010-11?international=true $\& r=U S \& I R=T \#$ holograms-onthe-field-instead-of-players-14

Budiu, R. (2018, November 25). The User Experience of Chatbots. Retrieved from nngroup. com: https://www.nngroup.com/articles/chatbots/

Performance Communications. (n.d.). The Future of Sports Fan. Performance Communications. Clickatell. (n.d.). 6 Tips to ensure that your chatbots are GDPR compliant. Retrieved from clickatell: https://www.clickatell.com/articles/ information-security/6-tips-chatbots-gdprcompliant/

CREATE-IT. (2017, May 10). Kenniscentrum Faculteit Digitale Media \& Creatieve Industrie. Retrieved from hva.nl: http://www.hva.nl/ create-it/gedeelde-content/lectorate/lectoraatcrossmedia/lectoraat-crossmedia.html

Decker, J. (2017, June 9). 3 Trends Changing the Fan Experience and the Future of Live Sports. Retrieved from huffingtonpost.com: https://www. huffingtonpost.com/entry/3-trends-changing-thefan-experience-and-the-future_us_59b01fcfe 4 b0bef3378cdce7
Deloitte. (2018). Deloitte's sports industry starting lineup Trends expected to disrupt and dominate 2018 .Deloitte. Dimensional Innovations. (2018). Fan Experience Trends to Watch in 2017. Retrieved from dimin.com: https://www. dimin.com/blog/fan-experience-trends-towatch-in-2017/

DSS. (2019). About-Digital Society School. Retrieved from digitalsocietyschool.org: https://digitalsocietyschool.org/about/

Flow.ai. (2019). Retrieved from flow.ai: https://flow.ai

GDPR. (n.d.). The EU General Data Protection Regulation (GDPR) is the most important change in data privacy regulation in 20 years. Retrieved from eugdpr: https://eugdpr.org/

Ismail, K. (2018, Jun 27). How Much Does It Cost To Build an Enterprise Chatbot?. Retrieved from cmswire.com: https://www.cmswire.com/ digital-experience/how-much-does-it-cost-tobuild-an-enterprise-chatbot/

Jai, T .M. \& King, N. J. (2016). Privacy versus reward: Do loyalty programs increase consumers'. Retrieved from deepdyve.com: https://www.deepdyve.com/lp/elsevier/privacyversus-reward-do-loyalty-programs-increaseconsumers-cAm0QIDyTh

Lardinois, F. (2016). XD supports vector design and website wireframing, and creating simple interactive click-through prototypes. Retrieved from techcrunch.com: https://tech-crunch.com/ 2016/03/14/adobe-launches-experience-designcc-a-new-tool-for-ux-designers/?guccounter=1

Martín, J. (2017, Feb 23). Design Framework for Chatbot. Retrieved from chatbotsmagazine.com: https://chatbotsmagazine. com/design-framework-for-chatbots-aa270 $60 \mathrm{c} 4 \mathrm{ea} 3$

Microsoft. (2016). Inclusive Microsoft Design. Microsoft.

Oracle. (2016). Can Virtual Experiences Replace Reality?. Retrieved from oracle.com: https://www.oracle.com/webfolder/s/delive ry_production/docs/FY16h1/doc35/CXRese archVirtualExperiences.pdf

Seo, E. (2017, Jan 20). 19 Best UX Practices for Building Chatbots. Retrieved from chatbotsmagazine.com: https://chatbotsmagazine.com/19-best-practices-for-buildingchatbots-3c46274501b2

Sustainable Development Goals. (2019). Retrieved from un.org: https://www.un.org/ sustainabledevelopment/sustainable-development-goals $/ 59$

Tankard, C. (2016). What the GDPR means for businesses. Turnali, K. (2013, Apr 10). Sports and Analytics: Fan Experience Matters. Retrieved from forbes.com: https://www. forbes.com/sites/sap/2013/04/10/sportsand-analytics-fan-experience-matters/\# $14 \mathrm{f} 426 \mathrm{da} 5 \mathrm{fd} 3$ 
van Hout, M. \& Gootjes, G. (2015). SCREAM! An Integrated Approach for Multidisciplinary. Retrieved from researchgate.net: https://www.researchgate.net/profile/Marc o_Van_hout2/publication/280922428_SCR EAM_AN_INTEGRATED_APPROACH FOR_MULTIDISICIPLINARY_DESIGN TEAMS_IN_HIGHER_EDUCATION/link s/5633c04d08ae758841121ab9/SCREAMAN-INTEGRATED-APPROACHFORMULTIDISICIPLINARY-DESIGNTEAMS-IN-HIGHER-EDUCATION.pdf
Vollmer, C. (2017). 2017 Entertainment and Media Trends Functional transformation to make businesses fan-centric .PwC. Wang, J. (n.d). Top Ten Trends on the Digital Fan Experience. Philadelphia: IBB Consulting Group.

What is QnA Maker. (2019). Retrieved from microsoft.com: https://docs.microsoft.com/ en-us/azure/cognitive-services/qnamaker/ overview/overview 